Currículo sem Fronteiras, v. 19, n. 3, p. 1324-1338, set./dez. 2019

\title{
A INTEGRAÇÃO CURRICULAR COMO COMPROMISSO ÉTICO NA CONTEMPORANEIDADE: educação, interdisciplinaridade e transdisciplinaridade
}

\author{
Rodrigo Avila Colla \\ Rede Municipal de Ensino de Esteio - RS
}

\begin{abstract}
Resumo
O artigo discute a necessidade de se promover diálogos de saberes para romper com a lógica disciplinar ainda tão presente no currículo escolar. Na hipótese defendida, educar sujeitos éticos na contemporaneidade passa por uma formação voltada para estabelecer relações e fomentadora de diálogos entre diferentes perspectivas e conhecimentos. O campo de estudos de currículo é tematizado no contexto brasileiro e o conceito de currículo é discutido à luz da contribuição de Corazza (2001). São introduzidos os conceitos de interdisciplinaridade e transdisciplinaridade como alternativas teórico-metodológicas que favorecem uma dinâmica dialógica na Educação. Como referencial teórico, são utilizadas principalmente as contribuições de Kant (1985; 2009), Maturana (1998; 2000; 2001) e Morin (2003a; 2003b; 2007a; 2007b).
\end{abstract}

Palavras-chave: Currículo Integrado; Ética e Educação; Interdisciplinaridade e Educação; Transdisciplinaridade e Educação.

\begin{abstract}
The article discusses the need to promote dialogues of knowledge to break with the disciplinary logic still so present in the school curriculum. In the hypothesis defended, educating ethical subjects in contemporary times goes through a formation aimed at establishing relationships and fostering dialogues between different perspectives and knowledge. The field of curriculum studies is thematized in the Brazilian context and curriculum concept is discussed in the Corazza's (2001) vision. The concepts of interdisciplinarity and transdisciplinarity are introduced as theoretical and methodological alternatives that favor a dialogic dynamic in Education. As theoretical reference, the contributions of Kant (1985; 2009), Maturana (1998; 2000; 2001) and Morin (2003a; 2003b; 2007a; 2007b) are used.
\end{abstract}

Keywords: Integrated Curriculum; Ethics and Education; Interdisciplinarity and Education; Transdisciplinarity and Education 


\section{Apresentação}

Pretendo estabelecer aqui um breve diálogo entre a ética kantiana e ideias mais recentes de Humberto Maturana (1998; 2000; 2001) e Edgar Morin (2003a; 2003b; 2007a; 2007b) que vêm refletindo sobre temas que contribuem para que se pense uma educação orientada pelos vieses da interdisciplinaridade e da transdisciplinaridade. Neste texto, esses autores são trazidos à tona a fim de "preparar o terreno" para que se possa pensar o caráter ético do conhecimento e as interimplicações do diálogo de saberes com a educação para a ética. Um currículo baseado no isolamento disciplinar, assim, estaria dificultando práticas que poderiam contribuir com a educação para a ética na contemporaneidade. Aliás, como salientam Silva et al. (2016, p. 100), "os discursos pedagógicos apontam para dimensões de ordem técnica e moral que evidenciam a gênese dos pensamentos sobre currículo, de sua aplicação e de seu desdobramento metodológico em sala de aula”. Em outras palavras, a imbricação entre ética e currículo se torna patente nos próprios discursos que, não por acaso, têm o intuito de pedagogizar de dado modo. Esses pendores pedagogizantes, manifestos inclusive nas falas e práticas docentes, constituem um curso (e esta é uma acepção da palavra currículo) organizado de maneira a cindir e estancar conhecimentos. Educar sujeitos éticos na contemporaneidade requer formação de habilidades para estabelecer relações e para saber dialogar com diferentes perspectivas e conhecimentos. A ética, ademais, em uma de suas acepções é entendida como a reflexão sobre os costumes e comportamentos, isto é, a disciplina filosófica voltada para a análise das normas e princípios que disciplinam e orientam as ações, bem como os desdobramentos destas nos contextos em que são empreendidas. Ora, se no curso do aprendizado a postura disjuntiva dificulta o estabelecimento de conexões dos conteúdos estudados com os fenômenos/acontecimentos (em muitos casos oriundos das ações humanas) o processo de reflexão acerca deles, de suas causas/motivações e desdobramentos, evidentemente sofre prejuízo. É importante notar que ambas as preocupações pedagógicas, embora mobilizem diferentes variáveis, se coadunam num mesmo processo. O diálogo de saberes e a disposição para o diálogo que acolhe o outro (e suas idiossincrasias, diferenças, perspectivas), imprescindível para alavancar o comportamento ético, se inserem num mesmo curso de integração que ajuda a criar uma cultura do diálogo. Buscarei, ao longo deste texto, apresentar noções que contribuem para que se pense a integração curricular como uma iniciativa pedagógico-epistemológica a serviço da formação de sujeitos éticos.

Antes de encetar essa discussão, contudo, é preciso introduzir o debate teórico referentes às alternativas teórico-metodológicas facilitadoras do diálogo interdisciplinar (introduzindo as noções de interdisciplinaridade e transdisciplinaridade) e a filosofia ética de Immanuel Kant. 


\section{Currículo, Interdisciplinaridade e Transdisciplinaridade}

Genylton da Rocha (2003) situa o surgimento das discussões sobre currículo no Brasil na primeira metade do século XX, mais precisamente na década de 1920, no contexto das reformas educativas implementadas pelos "Pioneiros da Escola Nova, mas explica que o campo só "adquiriu de fato a sua maturidade no início da década de 1970, quando surgiram os primeiros cursos de mestrado na área de currículo" (ROCHA, 2003, p. 44). Enquanto a influência da escola crítica marcou fortemente as produções científicas da década de 1980, preocupadas principalmente em refletir o currículo da escola fundamental, no início da década de 1990 o foco sociológico ganha bastante destaque. Contudo, é em meados desta década que os enfoques pós-modernos e pós-estruturais são incorporados ao pensamento curricular nacional na tentativa de se compreender a sociedade pós-industrial e a crescente produção de bens simbólicos (ROCHA, 2003).

Feita essa breve contextualização, o que é importante termos em mente aqui é que:

A grande importância que a história do currículo apresenta é o fato de "desnaturalizar" os conhecimentos presentes no currículo. É condição fundamental para a desmistificação desse construto esclarecer que ele é dotado de uma história, que ele é socialmente produzido e, consequentemente, sujeito às mudanças e às flutuações. (ROCHA, 2003, p. 47)

Na visão de Sandra Corazza (2001, p. 10), o currículo é um "dispositivo saber-poderverdade de linguagem" que pode ser pensado como um "ser falante" e, portanto, pode ser tomado como algo regido pelo funcionamento da linguagem.

Ao falar, um currículo é levado além de si próprio, pois o sentido do que diz encontra-se na linguagem de sua época e lugar, na qual está enredado. Também ao agir, um currículo sempre significa algo diferente do que do que faz e faz algo diferente do que significa. Este "algo diferente" é dado na relação existente entre as coisas significadas nos fazeres de um currículo e os signos usados para significá-las. (CORAZZA, 2001, p. 11-12)

Nesse sentido, um currículo motiva ações e discursos que atribuem significados e valores a ações, discursos, comportamentos, saberes, etc. Um currículo faz "algo diferente" daquilo que se propõe fazer: ele é "um ser falante, como nós, efeito e derivado da linguagem” (CORAZZA, 2001, p. 14) e, tal como nós, é multifacetado e impreciso. Há um abismo entre o que um currículo quer dizer e o que ele diz, pois suas ações só dão pistas das vontades de que estão impregnadas por meio de um "exército móvel de metáforas, metonímias, antropomorfismos” (NIETZSCHE, 2008, p. 27), isto é, suas verdades ora manifestas, ora veladas, crenças (in)úteis ${ }^{1}$ predeterminadas e com maior ou menor ênfase insufladas no curso formativo. Essas verdades são, invariavelmente, rebentas de um ser linguajeado inventor de cursos, o humano. 
Ao mesmo tempo, o currículo é organizado em disciplinas. Estas, podem ser definidas como categorias que organizam o conhecimento científico e instituem "nesse conhecimento a divisão e a especialização do trabalho respondendo à diversidade de domínios que as ciências recobrem" (MORIN, 2007a, p. 39).

Edgar Morin (2007a) não nega a contribuição que a disciplinaridade, isto é, a organização do conhecimento em campos, trouxe à ciência. Sem a delimitação dos objetos e dos domínios de competências que ela propicia, haveria o risco de conhecimentos se tornarem vagos e os métodos de investigação carecerem de rigor. $\mathrm{O}$ autor, porém, previne quanto aos riscos da instituição disciplinar, a saber: "simultaneamente, [há] um risco de hiperespecialização do investigador e um risco de coisificação do objeto estudado, percebido como coisa em si” (MORIN, 2007a, p. 40) que poderia ocasionar o esquecimento de que o objeto é oriundo de uma extração ou construção. Assim, "as ligações e solidariedades deste objeto com outros objetos tratados por outras disciplinas passam a ser negligenciadas" (Ibid, p. 40) bem como suas ligações e solidariedades com a totalidade de que faz parte.

Em obra intitulada O Paradigma Educacional Emergente, Maria Cândida Moraes (1997) se ampara fortemente em argumentos de Morin para defender "uma nova visão, mais complexa e sistêmica, da ciência e de suas implicações na educação" (MORAES, 1997, p. 85) a fim de que se alcance "uma compreensão mais abrangente e adequada dos aspectos envolvidos na multidimensionalidade do processo educacional" (Ibid, p. 85). Moraes (1997, p. 87) quer conceber o sistema educacional "como um sistema vivo, uma estrutura dissipadora de energia e de fenômenos educacionais que não funcionam como cadeias lineares de causa e feito; portanto, não existe uma única causa para este ou aquele defeito do sistema”. Para tanto, já não é mais possível que se promova a fragmentação disciplinar. No entendimento da autora, há um paradigma emergente na ciência que demanda outra postura por parte da área da Educação. Esta deve prezar pela capacidade de fomentar a conectividade entre diferentes conhecimentos e estabelecer pontos de encontro entre as disciplinas. Diante desse contexto, Moraes (1997) cita a interdisciplinaridade e a transdisciplinaridade como caminhos para superar a fragmentação e o isolamento disciplinar.

Ivani Fazenda, uma das principais autoridades brasileiras em estudos da interdisciplinaridade na educação, opina que um processo interdisciplinar "se consolida na ousadia da busca, de uma busca que é sempre pergunta, ou melhor, pesquisa". (FAZENDA, 2008, p. 9). Noutro lugar, a autora vai além:

Atitude de busca de alternativas para conhecer mais e melhor; atitude de espera perante atos não-consumados; atitude de reciprocidade que impele à troca, ao diálogo com pares idênticos, com pares anônimos ou consigo mesmo; atitude de humildade diante da limitação do próprio saber; atitude de perplexidade ante a possibilidade de desvendar novos saberes; atitude de desafio diante do novo, desafio de redimensionar o velho; atitude de envolvimento e comprometimento com os projetos e as pessoas neles implicadas; atitude, pois, de compromisso de 
construir sempre da melhor forma possível; atitude de responsabilidade, mas, sobretudo de alegria, revelação, de encontro, enfim, de vida (FAZENDA, 1991, p. 14, grifos da autora).

É possível afirmar que as ênfases da autora nos defrontam com o tema deste artigo. Isso porque ela dimensiona a interdisciplinaridade como uma busca repleta de atitudes que remetem à formação ética. As posturas de busca do conhecimento e de busca de um comportamento agregador e responsável não estão dissociadas. Trata-se, na verdade, de uma mesma postura.

Jurjo Torres Santomé (1998), ao abordar a interdisciplinaridade a partir de uma perspectiva histórica, destaca o dissenso entre os estudiosos em relação ao conceito. Enquanto uns justificam sua importância por acreditarem que é necessário reunificar o saber, outros a defendem como alternativa à dificuldade de delimitar os objetos de cada ciência. Neste segundo viés, a interdisciplinaridade chega a criar novas disciplinas (ou “interdisciplinas”) como a geofísica, a psicopedagogia e a etnomusicologia. O fato é que as discussões em torno da interdisciplinaridade são um fenômeno do século XX e se iniciaram num contexto em que há uma forte tendência à reorganização do conhecimento. "O termo interdisciplinaridade”, explica Torres Santomé (1998, p. 62), "surge ligado à finalidade de corrigir possíveis erros e a esterilidade acarretada por uma ciência excessivamente compartimentada e sem comunicação interdisciplinar”. Interdisciplinaridade, nesse sentido, é "fundamentalmente um processo e uma filosofia de trabalho que entra em ação na hora de enfrentar problemas e questões que preocupam em cada sociedade” (TORRES SANTOMÉ, 1998, p. 65); “é um objetivo nunca completamente alcançado e por isso deve ser permanentemente buscado” (TORRES SANTOMÉ, 1998, p. 66).

Enquanto a interdisciplinaridade pode ser compreendida como um processo dialógico que aproxima disciplinas fragmentadas visando a interligar conhecimentos, de acordo com Basarab Nicolescu, a transdisciplinaridade,

como o prefixo "trans" indica, diz respeito àquilo que está ao mesmo tempo entre as disciplinas, através das diferentes disciplinas e além de qualquer disciplina. Seu objetivo é a compreensão do mundo presente, para o qual um dos imperativos é a unidade do conhecimento. (NICOLESCU, 2000, p. 11, grifos do autor)

Nesse viés, a transdisciplinaridade quer um conhecimento que seja formado de modo condizente com a complexidade dos fenômenos por meio de enfoques plurais que atribuam sentidos a estes sem cindi-los em partes a serem analisadas por disciplinas separadas. Em vez disso, cabe considerar os fenômenos em suas totalidades, pois estas que traduzem a sua presentificação. Isto é, o fenômeno existe em sua totalidade - ela é seu modo de apresentação, de presentificação, de existência. A par disso, então, se pode agregar leituras acerca dos fenômenos, integrando-as numa compreensão que tenderá a ser mais completa e fidedigna em relação às particularidades do objeto estudado. 
Defendendo a ideia de que é preciso ir além da interdisciplinaridade, pois esta não tem contribuído para que, efetivamente, se possa desconstruir as fronteiras disciplinares, uma vez que cada disciplina continua querendo sua "soberania territorial” para só então se lançar ao diálogo, Edgar Morin (2007a, p. 52, grifos do autor) é categórico: "a ciência nunca teria sido ciência se não tivesse sido transdisciplinar". Isso porque se fizermos referência à Ciência, entendida como instituição e sistema por meio do qual se adquire conhecimento baseado em certos procedimentos e métodos - e, por isso, empregada no singular e com letra maiúscula - há uma unidade metodológica e "certo número de postulados implícitos" (Ibid, p. 52) que todas as ciências (muitas delas tornadas disciplinas e incluídas no currículo) compartilham. Maria da Conceição de Almeida (2017) explica que Ciência se refere a uma instância narrativa uniforme, monolítica, institucional e universal. A Ciência, de modo mais ou menos explícito, dependendo do contexto, reivindica e (se) apóia (n)o poder do conhecimento e tem assumido o papel de oráculo (ALMEIDA, 2017). A sua fragmentação em ciências ocorre a fim otimizar esse poder. Assim, a própria transdisciplinaridade inerente à Ciência gerou a disciplinaridade e fez com que se proliferassem ciências. Morin (2007a) sugere que essa velha transdisciplinaridade e o caráter por vezes reducionista que suas motivações encerram sejam superadas. Para tanto, é necessário uma nova transdisciplinaridade. Esta precisa "de um paradigma que, certamente, permita distinguir, separar, opor e, portanto, disjuntar relativamente estes domínios científicos, mas que, também, possa fazê-los comunicarem-se entre si, sem operar a redução" (MORIN, 2007a, p. 55).

Para Patrick Paul (2010, p. 147),

A transdisciplinaridade permite o desenvolvimento de uma nova metodologia de resolução dos problemas que esclarece as situações ao mesmo tempo complexas e paradoxais do imaginário, recompondo e renovando as relações delicadas entre episteme, mística e gnose que se observam em nosso estudo e que, de uma maneira ou de outra, compõem a realidade vivida da experiência humana.

Ora, a "realidade vivida" é sempre relacional, material e transcendente, portanto sua compreensão há de ser transdisciplinar - atravessando e indo além das perspectivas disciplinares. A realidade não é a soma das explicações disciplinares sobre ela, mas uma espécie de rede de relações que só pode ser expressa por um permanente diálogo que negocia novos sentidos e metodologias a fim de melhor apreender a complexidade da experiência.

Segundo Fernando Hernández (1998, p. 46), a transdisciplinaridade é um fenômeno de pesquisa que requer:

a) a formulação explícita de uma terminologia compartilhada por várias disciplinas e

b) uma metodologia compartilhada que transcende as tradições de campos de estudo que tenham sido concebidos de maneira fechada. 
A motivação de Hernández (1998) para discutir a transdisciplinaridade é semelhante à de Torres Santomé (1998) ao abordar a interdisciplinaridade, ambos querem buscar alternativas para um currículo integrado. A preocupação de ambos é interligar conteúdos que vêm sendo abordados de maneira fragmentada na tradição pedagógica.

\section{Notas sobre Ética e Educação a partir da visão Kantiana}

A filosofia de Kant, no que concerne à ética, é geralmente lembrada pelo imperativo categórico e por sua pretensão de universalização dos princípios éticos que regem o agir do sujeito. Nesse sentido, a proposição kantiana é muito mais moral do que ética. Aqui, no entanto, utilizarei o termo ética por ser mais apropriado ao caráter particular da discussão levada a cabo. O imperativo kantiano pode ser resumido pelo seguinte princípio: "nunca devo proceder de outra maneira senão de tal sorte que eu possa também querer que a minha máxima se torne uma lei universal” (KANT, 2009, p. 133, grifos do autor). Note-se que a pretensão de Kant (2009) era de que os princípios do agir se tornassem universais. A ação, nesse sentido, seria orientada pela razão e motivada pela autonomia da vontade, isto é, levada a cabo pelo sujeito livre que, ciente de sua liberdade e do caráter contingente de seus atos, opta por agir moralmente e se imbui dessa vontade em sua ação. Uma ação é, portanto, moral quando é motivada por uma vontade de moralidade.

Kant é um idealista e do mesmo modo que funda sua filosofia moral num modelo ideal de ação, estabelece algumas características ideais que definem o homem lúcido, ilustrado. Um sujeito ilustrado é aquele que atinge o estado de maioridade e, por intermédio de seu conhecimento, se torna senhor dos seus próprios atos e escolhas. Aquele que permanece na minoridade, por outro lado, delega suas decisões aos ilustrados, se eximindo, por “covardia”, no argumento do autor, a tomar parte na vida pública. É também a liberdade que pode levar ao esclarecimento. Mais especificamente: a liberdade de "fazer um uso público de sua razão em todas as questões” (KANT, 1985, p. 104, grifos do autor).

Maria Lúcia de Arruda Aranha (2001) explana que é primordialmente na adolescência que o indivíduo elabora sua vida moral. Segundo a autora, "nesse estágio do desenvolvimento humano o homem pode passar da heteronomia para a autonomia (auto = próprio). A lei a que ele obedece não mais é imposta do exterior (hetero = outro, diferente), mas ditada pelo próprio sujeito moral” (ARANHA, 2001, p. 120, grifos da autora). Entretanto, a formação ética dos indivíduos ocorre desde o início de suas vidas e se intensifica a partir do momento em que ingressam na escola. Por isso é preciso ter em mente que "não apenas a atividade pedagógica possui uma dimensão ética, mas também o fazer científico e o processo de aprendizagem e de ensino do fazer científico” (PAVIANI, 2005, p. 133). Este processo é levado a cabo na escola e, como bem salienta Paviani (2005), possui uma dimensão ética. Ora, um professor que se limita a transmitir informações aos alunos sem problematizá-las ou contextualizá-las, sem relacioná-las com outros conteúdos e propiciar experiências pedagógicas que ajudem a desenvolver a autonomia e a criticidade de seus alunos, sem permitir que estes perguntem e relacionem os saberes disciplinares com 
seus conhecimentos prévios, etc., estará, por certo, se valendo de um método e de uma postura que fomentam o comportamento heterônomo por parte de seus educandos. O mesmo ocorre com o projeto escolar e o currículo. Estes ensinam princípios e valores, quando não explicitamente, de modo implícito, mas igualmente potente. A escola, como sustenta Paviani (2005, p.121, grifos do autor), "não apenas pressupõe valores, mas também produz valores". Práticas educativas que compactuam com a dinâmica de um currículo de conhecimentos fragmentados, separados e desconectados do mundo da vida, assim, tendem a reforçar uma formação para a heteronomia e um comportamento que nega o diálogo. Nessa conjuntura, cabe ao educando a submissão ao conhecimento como algo normativo, antidemocrático, imposto verticalmente, e que tende a fazer pouco ou nenhum sentido em sua vida prática e, diante dessa carência de sentido, é assumido como algo que não se precisa discutir, mas aceitar; não requer diálogo, pois teve sua dimensão ética corrompida e ora funciona como uma espécie de alegoria de uma prática pedagógica que reproduz o isolamento, o silêncio. A ética requer a consideração do outro e é no convívio social que nos desenvolvemos como seres humanos. O ensino, por seu turno, passa por um processo de compreensão destes seres que somos em nossa relação com a natureza, a história, a realidade. "Essa compreensão”, ressalta Paviani (2005, p.121), “está presente no modo de agir com os outros e as coisas; ela explode no ato pedagógico".

\section{Educação, Conhecimento e Ética: dimensionando o diálogo de saberes}

Há mais de dois séculos a preocupação maior com a humanidade (e com a humanização) de fato residia em questões que diziam respeito ao indivíduo e ao seu comportamento para com o outro indivíduo humano, em que pese, vale ser dito, num contexto em que ainda havia escravidão e inexistia a igualdade de direito entre os sexos, por exemplo. Era uma época em que os princípios e valores iluministas vigoravam com pujança e, por conseguinte, influenciavam as propostas pedagógicas e o ideal de humanidade que se tinha, isto é, as qualidades que se acreditava serem essenciais à formação humana. Nesse quesito, John Locke (1632-1704), Jean-Jacques Rousseau (17121778) e, mais tarde, o próprio Kant (1724-1804), apenas para citar alguns exemplos, foram autores que exerceram grande influência.

Se para Kant era fundamental que se criasse princípios éticos que servissem para todos, e para todas as culturas, em qualquer parte do mundo, Maturana e Morin têm refletido sobre alguns tópicos bastante relevantes para que se pense uma educação que sirva para todos enquanto cidadãos globais, levando em conta a conjuntura contemporânea e as demandas éticas de nosso tempo.

Morin argumenta que a compreensão dos fenômenos requer um olhar contemplador da complexidade rompendo com o paradigma da ciência moderna. Nesse sentido, faz-se mister o diálogo interdisciplinar (ou diálogo de saberes).

Ao mesmo tempo, em relação à perspectiva predominante na modernidade, a acepção dos termos humanidade e humanização também passaram por transformações. Porém, se 
superamos algumas limitações no que se refere à consideração da ética como privilégio de uma elite e centrada estritamente nos interesses humanos e cujos princípios deveriam ser passíveis de universalização, incorremos numa série de circunstâncias ameaçadoras advindas, de certo modo, de uma tendência de considerarmos o ser humano como indivíduo isolado ou, se em relação, apenas em relações humanas. Essas circunstâncias a que me refiro de alguma forma estão ligadas à falta de atenção para com as interações entre o homem e o meio. Se em parte a ética animal e a ética ambiental, por exemplo, ganharam alguma relevância nos últimos tempos, a tendência dominante ainda é a de se pensar a ética como disciplina filosófica que reflete o agir humano e as suas implicações a outros seres humanos.

Na construção, por assim dizer, dessa ética estritamente humana, ao longo dos tempos, parece ter sido pouco considerada a condição relacional e de formação do homem com o meio. Nas reflexões sobre o currículo escolar, analogamente, foi preterida a preocupação trans-relacional entre os saberes. Uma disciplina, salvo raras exceções, é um módulo fechado que trata de certos conteúdos que pouco dialogam com os de outras disciplinas. Projetos que integram saberes em busca da resposta para um problema ou temas geradores de projetos de estudos ${ }^{2}$ são práticas que, embora venham aparecendo com mais recorrência, ainda são escassas nas escolas. Na maior parte dos casos, foram consolidadas nas instituições escolares fronteiras entre as áreas de conhecimento de forma que comumente não se via no currículo relação alguma com a prática, com o cotidiano e, porque não dizer, com o caráter humano dos saberes disciplinarizados e "superespecializados". Cabe reiterar que, lentamente, essa lógica demonstra cair em descrédito e há inúmeros exemplos de práticas pedagógicas exitosas que contemplam tanto o diálogo entre as disciplinas quanto a aplicabilidade dos saberes, ou seja, a sua relação com o mundo da vida. Trata-se, entretanto, de uma tímida mudança se considerarmos o sistema educativo como um todo. A regra ainda é a disciplinarização e a escassez de diálogo entre os conhecimentos. Para Maturana,

Uma das coisas boas da transdisciplinaridade é que não podemos ser acusados de pisar onde não devemos pisar quando falamos de coisas que não pertencem à nossa própria disciplina. Assim, estaremos cruzando fronteiras livremente, sem sermos acusados de transgressão, apesar de podermos ser acusados de estar enganados, o que é diferente. (MATURANA, 2000, p. 83)

Esse excerto remete a algumas colocações bastante interessantes de Boaventura de Sousa Santos (2008) sobre o novo paradigma científico. Em sua obra Um Discurso sobre as Ciências, o autor ressalvava o aspecto interdisciplinar do "novo conhecimento" se referindo a ele como um terreno fértil para o surgimento de campos da ciência que integrem saberes até agora cindidos. O diálogo de saberes, assim, constitui um novo aspecto do conhecimento, mas a ideia é de que chegamos a um ponto em que somente esse diálogo nos permitirá continuar avançando. Somente uma nova concepção do que é o próprio “conhecer" - e de seu caráter eminente e crescentemente dialógico - poderá nos propiciar 
um conhecimento mais próximo da desejada congruência com a complexidade. Edgar Morin (2007b, p. 14) utiliza a expressão "conhecimento pertinente” para se reportar a uma forma de saber "capaz de apreender problemas globais e fundamentais para neles inserir os conhecimentos parciais e locais". O autor menciona essa expressão no contexto de uma obra em que se propõe pensar Os Sete Saberes Necessários à Educação do Futuro. O livro partiu de uma iniciativa da UNESCO, em 1999. Ficou a cargo de Morin sistematizar saberes que considerava indispensáveis para se pensar a educação do milênio porvir. O autor propôs os seguintes eixos:

- As cegueiras do conhecimento: o erro e a ilusão.

- Os princípios do conhecimento pertinente;

- Ensinar a condição humana;

- Ensinar a identidade terrena;

- Enfrentar as incertezas;

- Ensinar a compreensão;

- A ética do gênero humano.

A preocupação de Morin (2007b) está centrada, sobretudo, em conectar problemas e saberes dissociados no curso da história do conhecimento. O conhecimento pertinente por ele defendido requer, assim: a apreensão de problemas globais e o uso de conhecimentos locais no tratamento dado a eles; a vinculação entre as partes e a totalidade; a reunião dos saberes fragmentados e sua contextualização para a compreensão de um mundo complexo e da condição humana levando em conta suas múltiplas dimensões.

Conforme Morin (2007b, p. 36),

O conhecimento pertinente deve enfrentar a complexidade. Complexus significa o que foi tecido junto; de fato, há complexidade quando elementos diferentes são inseparáveis constitutivos do todo (como o econômico, o político, o sociológico, o psicológico, o afetivo, o mitológico), e há um tecido interdependente, interativo e inter-retroativo entre o objeto de conhecimento e seu contexto, as partes e o todo, o todo e as partes, as partes entre si. Por isso, a complexidade é a união entre a unidade e a multiplicidade.

Em outra de suas obras, Morin (2003b, p. 21) parafraseia o poeta Antonio Machado para defender que não deve haver um molde para o novo método científico, mas que ele deve ser criado na própria trajetória do pesquisador: "caminhante, são tuas pegadas o caminho e nada a mais; caminhante, não há caminho, se faz caminho ao andar”.

Inspirado pela beleza desses versos e pela reflexão de Morin (2003b), tendo a pensar que o caminho do conhecimento complexo - e, a meu ver, o caminho da educação na contemporaneidade - está justamente nesse diálogo de saberes, diálogo que se vai tramando ao dialogar e creio que a educação é a instância privilegiada para a intermediação entre esses saberes e a própria arena na qual estes podem ser colocados em diálogo desde a base da formação humana. Enquanto esfera propícia para tal empresa, a educação orientada por 
esse princípio propiciaria um domínio de conduta marcado pela “objetividade-entreparênteses”. Segundo Maturana (1998), essa postura é caracterizada pelo respeito pela diferença e pelo "reconhecimento do outro enquanto legítimo outro na convivência”. À emoção que orienta esse reconhecimento Maturana (1998) dá o nome de amor. Para o autor, trata-se de uma emoção primordialmente humana que, por estar baseada na aceitação do outro, funda o pendor para a sociabilidade.

Nesse sentido, não se deve ter medo de “pisar” num território que não é o seu (Cf. MATURANA, 2000), pois o debate interdisciplinar, tendo em seu horizonte o objetivo de se criar projetos transdisciplinares, deve acolher o outro enquanto legítimo outro e levar em conta que ele é o detentor de um saber diverso que tende a agregar valor ao entendimento acerca do fenômeno em discussão. No domínio emotivo que sustenta a "objetividade-entreparênteses" e a par da irredutibilidade dos fenômenos, a saber, de seu caráter complexo, o outro não somente oferece outra perspectiva, mas opera em outra realidade não menos legítima que a minha. Ao mesmo tempo, só essa emoção e a atitude epistemológica por ela fundada podem servir de fundamentos a um verdadeiro diálogo - em que diferentes logos devem ser tomados como igualmente legítimos e passíveis de agregar conhecimentos.

Recorramos às palavras do próprio Maturana (2001) para compreender como os sistemas racionais, sendo produções humanas, se originam em circunstâncias em que as emoções têm papel preponderante. Segundo o autor,

na medida em que as emoções fundam os espaços de ação, elas constituem os espaços de ação. Sim, não há nenhuma atividade humana que não esteja fundada, sustentada por uma emoção, nem mesmo os sistemas racionais, porque todo sistema racional, além disso, se constitui como um sistema de coerências operacionais fundado num conjunto de premissas aceitas a priori. E essa aceitação a priori desse conjunto de premissas é o espaço emocional. E quando se muda a emoção, também muda o sistema racional. (MATURANA, 2001, p. 47, grifo do autor)

Portanto, quando se defende uma postura que fomente o diálogo de saberes e os integre em prol de um conhecimento prudente, se está preconizando uma abertura a um domínio de emoções que de certa forma aproxima a ética e a epistemologia. Cabe, no entanto, enfatizar que

As reflexões éticas nunca vão além do domínio social em que surgem. Por isso é que uma argumentação sobre o respeito, a ética, os direitos humanos não convence a ninguém que já não esteja convencido. Porque não é a razão que justifica a preocupação pelo outro, mas é a emoção. Se estou na emoção de aceitação do outro, o que lhe acontece tem importância e presença para mim. (MATURANA, 2001, p. 48, grifo do autor) 
Contudo, a postura diante da busca pelo conhecimento também reflete as emoções de que os sujeitos estão imbuídos. Essas emoções serão determinantes no tipo de conhecimento que se estará construindo.

Morin (2003a) destaca a importância das ciências naturais na compreensão da condição humana e, em sua escrita, também transparece a defesa da renovação e reunião dessas ciências:

O estudo da condição humana não depende apenas do ponto de vista das ciências humanas. Não depende apenas da reflexão filosófica e das descrições literárias. Depende também das ciências naturais renovadas e reunidas, que são: a Cosmologia, as ciências da Terra e a Ecologia. O que essas ciências fazem é apresentar um tipo de conhecimento que organiza um saber anteriormente disperso e compartimentado. (MORIN, 2003a, p. 35)

Note-se que a própria cisão entre ciências humanas e naturais sugere certa isenção humana em relação àquilo que é "natural" e a não naturalidade daquilo que é humano. As implicações dessa cisão são largamente discutidas pelos filósofos da ciência e por epistemólogos. Não cabendo aqui um aprofundamento nesse tema, basta tomarmos o excerto de Morin (2003a) como matéria-prima para lançarmos algumas indagações: É prudente estabelecer uma cisão que parece trair a compreensão da complexidade da condição humana? Será ético depurar o ser humano de sua naturalidade?

Nesse viés, Morin (2003a, p. 40, grifos do autor) chama a atenção para o "caráter duplo e complexo do que é humano: a humanidade não se reduz absolutamente à animalidade, mas, sem animalidade, não há humanidade". Essa colocação pode soar um tanto óbvia, mas no momento histórico em que vivemos é imprescindível reafirmá-la. Os grandes avanços científicos e tecnológicos que propiciaram à espécie humana o reinado planetário, por assim dizer, associados a uma série de outras variáveis, também influenciaram um processo de afastamento da animalidade acompanhando de um grande afã de distinção do humano em relação a outras espécies animais (Cf. COLLA, 2018, p. 40-121).

A meu ver, uma nova concepção ética não apenas humana, mas da humanidade humanidade esta interligada com o planeta em sua complexidade e contempladora da animalidade que lhe é inerente - requer a assunção legítima das mais diversas relações, dos múltiplos conhecimentos e abordagens, da infinidade de caminhos a serem seguidos e de caminhantes que os seguem. Estes, aliás, são agentes capazes de se desviar de seus caminhos e criar novos. Uma ética da humanidade precisa ainda do diálogo entre todas essas instâncias do conhecimento. O conhecimento é produto humano e, o sendo, diz algo de seu produtor. Para bem compreender a condição humana, ou conhecê-la de modo prudente, é imprescindível que os diferentes conhecimentos construídos no curso filogenético e histórico em que nos constituímos humanos a este modo sejam contemplados e integrem debates num contexto democrático. Um debate dessa natureza pode propiciar condições para a transformação das condições de vida dos seres humanos em consonância com as demandas éticas atuais. Necessitamos, como declara Maturana (1998), de uma 
“conspiração democrática” em que estejamos dispostos a conviver na humanidade - no sentido de conviver unidos pelo sentimento identitário de sermos humanos - e isto requer integração de diferentes leituras acerca do humano e de diferentes saberes que, mesmo nos casos em que se enquadram no rol das ciências naturais, sempre, invariavelmente, têm algo de humano, estão impregnados de intencionalidades, vícios e virtudes que revelam traços da condição humana. Democracia aqui não deve ser entendida meramente como o governo da maioria, mas como um governo que conspira para que todos possam auferir (auto)governabilidade. Ao mesmo tempo, espera-se dos indivíduos que tomam parte nessa conspiração a gradativa compreensão do caráter animal-multicultural do humano. Torres Santomé (1998, p. 10), discorrendo sobre o movimento pedagógico a favor da globalização e da interdisciplinaridade, situa o nascimento desta a partir das "reivindicações progressistas de grupos ideológicos e políticos que lutavam por uma maior democratização da sociedade”. Não por acaso, diante da tarefa de se pensar em alternativas para a integração curricular e para o diálogo entre diferentes áreas do conhecimento, surge a democracia como uma categoria fundamental. Conspirar democraticamente, assim, passa por estabelecer um pacto que burle a rigidez e o isolamento de currículos organizados em disciplinas estanques. Conspirar por um processo educativo democrático, além de oferecer condições de acesso e permanência à escola e de reivindicar o respeito pela diferença, implica também criar condições para que o diálogo ocorra em todas as instâncias da Educação. Uma educação para a formação de sujeitos éticos não pode se furtar de abordar o conhecimento de maneira relacional e democrática. A esta altura cabe retomar Paviani (2005): a dimensão ética da educação transcende os valores ensinados na escola e a organização escolar, impregnando todo o processo de ensino-aprendizagem e a vida escolar como um todo.

Uma ética que sirva para todos, como queria Kant, requer a contemplação da vida enquanto potência legítima nas relações e o (re)conhecimento do próprio saber com seus múltiplos caminhos e dimensões de aplicabilidade. Nesse sentido, urgimos por um conhecimento vivo e conectado com o mundo da vida. Para tanto, faz-se mister o diálogo de saberes que convém ser encetado desde a base da formação humana. Assim, creio sejamos capazes de andar, embora em distintos caminhos, numa passada que esteja em coerência com a vida, com a dimensão planetária de nossa existência e com o sentimento de humanidade capaz de nos unir em nossas diferenças. Vida, aliás, que, para Nietzsche, é “aquele poder obscuro, impulsionador, inesgotável que deseja a si mesmo" (NIETZSCHE, 2003, p. 30), potência de busca que nos conduz a nos aproximarmos uns dos outros e que nos mantêm em permanente movimento rumo ao desconhecido. Movimento que se intensifica com diálogos sobre aquilo que conhecemos, que nos harmoniza à medida que nos movimentamos mais intensamente, que infla a vida de mais e mais desejo de viver. 


\section{Notas}

1. Na óptica do jovem Nietzsche (Cf. 2008), verdades são crenças úteis. A crença na verdade está a serviço do instinto de conservação.

2. Torres Santomé (1998) destaca duas modalidades clássicas de integração curricular, a saber: os centros de interesse decrolyanos e o método de projetos. Utilizei a expressão “temas geradores” por ela ter sido bastante popularizada em nosso país, sobretudo por Paulo Freire. Apesar de José Carlos Libâneo (Cf. 2002) situar Freire e Decroly em tendências pedagógicas distintas, é possível considerar as propostas de ambos como alternativas que visam a mobilizar os educandos em torno de algo que seja significativo para eles. Entretanto, cabe frisar que o método de Decroly é centrado na criança e abrange sua formação como um todo enquanto o de Freire é voltado inicialmente para a alfabetização de adultos. Outra iniciativa que merece destaque enquanto esforço de integração curricular é a de Busquets et al. (1998). Em obra intitulada Temas Transversais em Educação: bases para uma formação integral, esses autores propõem uma inversão de eixos que daria aos temas transversais o estatuto antes ocupado pelas disciplinas. Desse modo, a abordagem dos conteúdos ou conhecimentos disciplinares estaria a serviço de um processo de sustentação dos temas transversais como principais objetos da educação, ou seja, como assuntos mais relevantes e urgentes.

\section{Referências}

ALMEIDA, Maria da Conceição de. Ciências da Complexidade e Educação: razão apaixonada e politização do pensamento. Curitiba: Appris, 2017.

ARANHA, Maria Lúcia de Arruda. Filosofia da Educação. São Paulo: Moderna, 2001.

BUSQUETS, Maria Dolors, et al. Temas Transversais em Educação: bases para uma formação integral. São Paulo: Ática, 1998.

COLLA, Rodrigo Avila. Animalidade e Educação Moral: cenas da vida selvagem na escola. 2018.277 f. Tese (Doutorado em Educação) - Escola de Humanidades, Pontifícia Universidade Católica do Rio Grande do Sul, Porto Alegre.

CORAZZA, Sandra Mara. O Que Quer um Currículo? Petrópolis, RJ: Vozes, 2001.

FAZENDA, Ivani C. Arantes. Interdisciplinaridade: história, teoria e pesquisa. Campinas, SP: Papirus, 2008.

Interdisciplinaridade: um projeto em parceria. Coleção Educar, v. 13. São Paulo: Loyola, 1991.

HERNÁNDEZ, Fernando. Transgressão e Mudança na Educação: os projetos de trabalho. Porto Alegre: ArtMed, 1998.

KANT, Immanuel. Fundamentação da Metafísica dos Costumes. São Paulo: Discurso Editorial; Barcarolla, 2009.

Textos Seletos. Petrópolis, RJ: Vozes, 1985.

LIBÂNEO, José Carlos. Democratização da Escola Pública. São Paulo: Loyola, 2002.

MATURANA, Humberto. Cognição, Ciência e Vida Cotidiana. Belo Horizonte: Ed. da UFMG, 2001.

Emoções e Linguagem na Educação e na Política. Belo Horizonte: Ed. da UFMG, 1998.

Transdisciplinaridade e Cognição. In: Educação e Transdisciplinaridade. Brasília: UNESCO, 2000.

MORAES, Maria Cândida. O Paradigma Educacional Emergente. Campinas, SP: Papirus, 1997.

MORIN, Edgar. A Cabeça Bem-feita: repensar a reforma - reformar o pensamento. Rio de Janeiro: Bertrand Brasil, 2003. 
Articulação de Saberes. In: ALMEIDA, Maria da Conceição de; CARVALHO, Edgard de Assis (Orgs.). Educação e Complexidade: os sete saberes e outros ensaios. São Paulo: Cortez, 2007.

Educar na Era Planetária: o pensamento complexo como método de aprendizagem pelo erro e incerteza humana. São Paulo: Cortez, 2003.

. Os Sete Saberes Necessários à Educação do Futuro. Brasília: UNESCO, 2007.

NICOLESCU, Basarab. Um Novo Tipo de Conhecimento - Transdisciplinaridade. In: Educação e Transdisciplinaridade. Brasília: Unesco, 2000.

NIETZSCHE, Friedrich W. Segunda Consideração Intempestiva, Da Utilidade e Desvantagem da História para a Vida. Rio de Janeiro: Relume Dumará, 2003.

. Sobre Verdade e Mentira. São Paulo: Hedra, 2008.

SANTOS, Boaventura de Sousa. Um Discurso sobre as Ciências. São Paulo: Cortez, 2008.

SILVA, João Alberto da et al. O Currículo dos Anos Iniciais: campo de tensão e controvérsias. Currículo sem Fronteiras, v. 16, n. 1, p. 99-112, jan./abr. 2016.

PAUL, Patrick. A Imaginação como Objeto do Conhecimento. In:

SOMMERMAN, Américo; MELLO, Maria F. de; BARROS, Vitória M. de (Orgs). Educação e Transdisciplinaridade II. São Paulo: TRIOM, 2002. Disponível em: <http://unesdoc.unesco.org/images/0012/001297/129707POR.pdf>. Acesso em 16 de maio de 2018.

PAVIANI, Jayme. Problemas de Filosofia da Educação - o cultural, o político, o ético na escola, o pedagógico, o epistemológico no ensino. Caxias do Sul, RS: Educs, 2005.

ROCHA, Genylton Odilon Rêgo da. A pesquisa sobre currículo no Brasil e a história das disciplinas escolares. In: GONÇALVES, Luiz Alberto de Oliveira (Org.). Currículo e Políticas Públicas. Belo Horizonte: Autêntica, 2003.

TORRES SANTOMÉ, Jurjo. Globalização e Interdisciplinaridade: o currículo integrado. Porto Alegre: Editora Artes Médicas Sul Ltda., 1998.

\section{Correspondência}

Rodrigo Avila Colla: Professor da Rede Municipal de Ensino de Esteio - RS.

E-mail: rodrigo.a.colla@gmail.com

Texto publicado em Currículo sem Fronteiras com autorização do autor 